This document is the Accepted Manuscript version of a Published Work that appeared in final form in Journal of the American Chemical Society, copyright (c) American Chemical Society after peer review and technical editing by the publisher. To access the final edited and published work see https://doi.org/10.1021/jacs.9b11895. 


\title{
Influence of Solvent in Crystal Engineering: A Significant Change to the Order-Disorder Transition in Ferrocene
}

\author{
Joseph C. Bear, ${ }^{\dagger}$ Jeremy K. Cockcroft, ${ }^{*}$, and Jeffrey H. Williams $^{\S}$ \\ †School of Life Sciences, Pharmacy and Chemistry, Kingston University, Penrhyn Road, Kingston upon Thames, KT1 2EE, \\ United Kingdom \\ ${ }^{*}$ Department of Chemistry, Christopher Ingold Laboratories, University College London, 20 Gordon Street, London WC1H \\ 0AJ, United Kingdom \\ ${ }^{\S}$ Retired. Current address: Montpellier, France.
}

Supporting Information

\begin{abstract}
We present the structure of a novel solvate adduct formed by dissolving ferrocene, $\mathrm{FeCp}_{2}$, in hexafluorobenzene, $\mathrm{C}_{6} \mathrm{~F}_{6}$. This adduct demonstrates the remarkably strong interactions between the five-membered aromatic rings of $\mathrm{FeCp}_{2}$ and the six-membered aromatic ring of $\mathrm{C}_{6} \mathrm{~F}_{6}$. These molecular interactions are sufficiently strong and anisotropic to change the temperature of the order-disorder transition of the ferrocene molecule from below $c a$. $164 \mathrm{~K}$ to RT. No solvate adduct could be formed between benzene and $\mathrm{FeCp}_{2}$. These observations will be of particular relevance to the crystal engineering community whose goal is the design of solids with bespoke properties.
\end{abstract}

Ferrocene, bis(cyclopentadienyl)iron(II), $\mathrm{Fe}\left(\mathrm{C}_{5} \mathrm{H}_{5}\right)_{2}$ or $\mathrm{FeCp}_{2}$, was discovered in 1951, the first and one of the most stable metallocenes. $^{1-3}$ It was a discovery that re-invigorated organometallic chemistry, and over the last 68 years, thousands of metallocenes and their derivatives have been synthesised, and used as catalysts in laboratories and in technological processes. ${ }^{4-5}$ Solid ferrocene exhibits dynamic disorder of the cyclopentadienyl $(\mathrm{Cp})$ rings at ambient temperature but transforms to a more ordered structure with a semi-eclipsed conformation of the $\mathrm{Cp}$ rings below $c a$. $164 \mathrm{~K}^{6-9}$ A fully eclipsed form has been reported in recrystallization experiments below $100 \mathrm{~K} .^{10}$

As one of the few air-stable metallocenes, ferrocene is an ideal component for fundamental studies in crystal engineering. The central idea behind our investigation of this and other binary adducts involving small aromatic molecules is that it is possible to use simple ideas of molecular electrostatics to explain observed crystal structures, and to predict novel structures. The first question raised in this study was whether benzene and / or hexafluorobenzene would form a solvate adduct / co-crystal with ferrocene. $\mathrm{C}_{6} \mathrm{~F}_{6}$ has no dipole but a large positive quadrupole moment $(+32 \pm$ $\left.1.7 \times 10^{-40} \mathrm{Cm}^{2}\right)^{11}$ and $\mathrm{FeCp}$ has a large negative quadrupole $(-30$ $\left.\pm 7 \times 10^{-40} \mathrm{Cm}^{2}\right)^{12}$ similar to that of benzene $\left(-29 \pm 1.7 \times 10^{-40}\right.$ $\mathrm{Cm}^{2)}{ }^{11}$ When considering the structure of binary adducts, the combination of positive and negative quadrupoles maximizes the electrostatic interaction between rings, and generates a face-toface pairing of the planar molecules, which form closely-packed columns. $^{13-16}$

Thus, we sought to synthesise the prototype metallocene solvate adduct, $\mathrm{C}_{6} \mathrm{~F}_{6}: \mathrm{FeCp}_{2}$. Given the formation of $\mathrm{C}_{6} \mathrm{~F}_{6}: \mathrm{FeCp}_{2}$ and our inability to form the benzene analogue, two further questions are raised: what is the effect on the physical properties of the
$\mathrm{FeCp}_{2}$ co-former and, secondly, how do the anisotropic nature of interactions between 5 - and 6-membered rings differ from the interactions between pairs of 6-membered rings, as in e.g. the prototypical adduct $\mathrm{C}_{6} \mathrm{~F}_{6}: \mathrm{C}_{6} \mathrm{H}_{6}$ and its methyl derivatives? ${ }^{13-16}$

The literature on ferrocene co-crystals and solvates consists of studies on true ferrocene adducts ${ }^{17-20}$ and on ferrocene derivatives. $^{21-23}$ Pertinent to this study are those involving co-crystals of $\mathrm{FeCp}_{2}$ with fluoronated aromatics, e.g. decafluorobiphenyl, ${ }^{17}$ octafluoronaphthelane, ${ }^{18}$ and decafluorophenanthrene, ${ }^{19}$ and nonfluoronated aromatic molecules such as pyrene. ${ }^{20}$ In the latter, the structure is characterized by a side-on interaction between both $\mathrm{Cp}$ rings and the plane of the pyrene molecule. By contrast, both of the co-crystals of perfluoro molecules and $\mathrm{FeCp}_{2}$ exhibit interactions involving the respective molecular quadrupolar moments between the faces of the perfluoroarene and the $\mathrm{Cp}$ rings.

A study of the structure of $\mathrm{C}_{6} \mathrm{~F}_{6}: \mathrm{FeCp}_{2}$ as a function of temperature allows one to probe weak electrostatic interactions in the solid state including neighbouring $\mathrm{C}-\mathrm{F}$ and $\mathrm{H}-\mathrm{C}$ bond dipoles and intermolecular quadrupolar interactions. Understanding these weak interactions has particular importance in the pharmaceutical sector, where a variety of fluorinated active pharmaceutical ingredients have been developed. ${ }^{24}$ This study is of special interest to the crystal engineering ${ }^{25-27}$ and structure simulation ${ }^{28-30}$ communities as it highlights and scrutinizes some of the fundamental weak interactions that hold molecules together in solid materials.

The compound $\mathrm{C}_{6} \mathrm{~F}_{6}: \mathrm{FeCp}_{2}$ was synthesized by dissolving ferrocene in excess hot $\mathrm{C}_{6} \mathrm{~F}_{6}$ before allowing the solution to cool naturally. The resulting orange crystals were found to be susceptible to decomposition in the absence of $\mathrm{C}_{6} \mathrm{~F}_{6}$ vapor, and therefore single-crystal X-ray diffraction (SXD) experiments were performed using glass capillaries (see Additional Experimental Details in the Supporting Information). The structure of $\mathrm{C}_{6} \mathrm{~F}_{6}: \mathrm{FeCp}_{2}$ was determined by SXD as a function of temperature from $100 \mathrm{~K}$ up to its decomposition temperature at $c a$. $309 \mathrm{~K}$, an exact decomposition temperature being difficult to determine. Analysis of diffracted intensity, unit cell volume, and structure all indicated a transition from a structure with ordered $\mathrm{FeCp}_{2}$ molecules (denoted phase II) to one with disordered molecules (denoted phase I) at about RT (see Figures 1 and 2). A transition temperature of $c a$. $295 \mathrm{~K}$ was confirmed by DSC (see Supporting Information).

At $100 \mathrm{~K}$, the structure of $\mathrm{C}_{6} \mathrm{~F}_{6}: \mathrm{FeCp}_{2}$ is composed of approximately close-packed columns of alternating $\mathrm{C}_{6} \mathrm{~F}_{6}$ and $\mathrm{FeCp}_{2}$ molecules (see Figure S1) with the $\mathrm{C}_{6} \mathrm{~F}_{6}$ arranged face on to the $\mathrm{Cp}$ ring. This optimizes the intermolecular quadrupolar forces between the two components, which is the main driving force for 
structural arrangement. The columnar arrangement is maintained through the order-disorder transition right up to the crystal's decomposition into its constituent components.

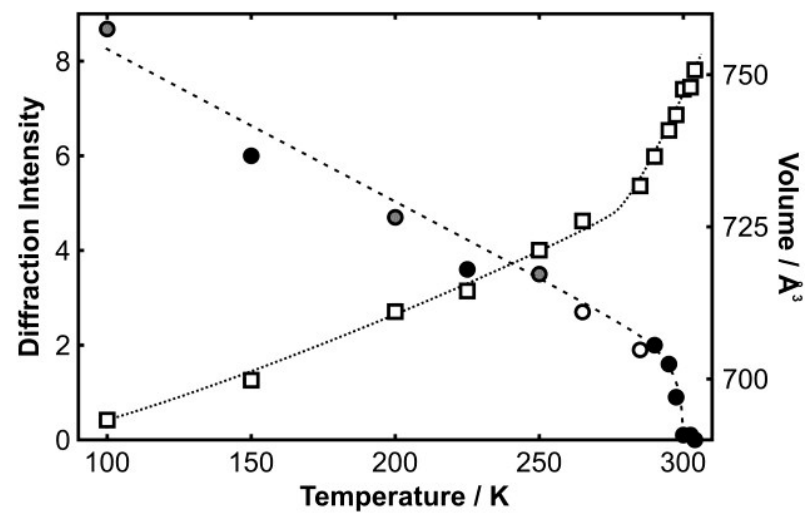

Figure 1. Unit cell volume (right-hand axis) of $\mathrm{C}_{6} \mathrm{~F}_{6}: \mathrm{FeCp}_{2}$ as a function of temperature (data points shown as open squares). Mean diffraction intensity of reflections whose $h k l$ indices satisfy the extinction condition $h+l=2 n+1$ is shown as a function of temperature (data points shown as circles). Different crystals of $\mathrm{C}_{6} \mathrm{~F}_{6}: \mathrm{FeCp}_{2}$ used in the experiments are represented as grey (crystal number \#4), open (\#8), and filled (\#10) circles. Dotted and dashed lines are a guide to the eye. The graph shows that although the onset of disorder starts at about $285 \mathrm{~K}$, the transition to phase I is close to RT at which point the mean diffracted intensity of these reflections has dropped to zero.

At low temperature $(100 \mathrm{~K})$, the $\mathrm{FeCp}_{2}$ molecules in the solvate adduct are clearly ordered with eclipsed $\mathrm{Cp}$ rings, as can be seen at $250 \mathrm{~K}$ albeit with larger atomic displacements (see Figure 2). However, above the transition temperature at about RT and over a narrow range $(c a .10 \mathrm{~K})$ of temperature, the $\mathrm{Cp}$ rings are dynamically disordered due to stochastic jump rotations about the 5-fold axis of the $\mathrm{FeCp}_{2}$ molecule. This is in marked contrast to the order-disorder behavior in pure $\mathrm{FeCp}_{2}$ where disorder occurs below $c a .164 \mathrm{~K}^{7}$ This is significant since $\mathrm{C}_{6} \mathrm{~F}_{6}$, a molecule conventionally thought of as a solvent, has changed the transition temperature by $c a .130 \mathrm{~K}$, and hence the physical property of $\mathrm{FeCp}_{2}$, by forming a weakly-bound adduct.
Figure 3 illustrates the face-on interaction between the 5membered $\mathrm{Cp}$ rings and the 6-membered $\mathrm{C}_{6} \mathrm{~F}_{6}$ ring in the columnar structure. As observed in related studies on adducts of $\mathrm{C}_{6} \mathrm{~F}_{6}$ with methyl-substituted benzenes, ${ }^{14-16}$ there is a similar tilt of the planes of the $\mathrm{C}_{6} \mathrm{~F}_{6}$ rings with respect to the column axis $\left(\mathrm{ca} .18^{\circ}\right.$ at $100 \mathrm{~K}$ ). However, it is by tilting one aromatic ring relative to the other that the most favorable electrostatic interaction is obtained between a planar five-membered aromatic ring and a planar sixmembered aromatic ring. Thus, in marked contrast to methylsubstituted benzenes, the asymmetric interaction between the $\mathrm{C}-\mathrm{H}$ and $\mathrm{C}-\mathrm{F}$ bond dipoles of the 5 and 6 -membered rings leads to an increased tilt of $c a .8 .5^{\circ}$ between the $\mathrm{Cp}$ rings of the $\mathrm{FeCp}_{2}$ molecule and the $\mathrm{C}_{6} \mathrm{~F}_{6}$ molecules.

In addition to the quadrupole interactions between facing rings, the structure is maintained via the $\mathrm{C}-\mathrm{H}$ and $\mathrm{C}-\mathrm{F}$ bond dipole interactions in adjacent columns (see Figure S2). Furthermore, a longer range electrostatic interaction between the central $\mathrm{Fe}$ atom and $\mathrm{F}$ atoms in $\mathrm{C}_{6} \mathrm{~F}_{6}$ molecules to the side of the $\mathrm{FeCp}_{2}$ may be important for columnar integrity. This intercolumnar interaction weakens noticeably with increasing temperature (see Figure S5).

The ordering of the $\mathrm{Cp}$ rings in $\mathrm{C}_{6} \mathrm{~F}_{6}: \mathrm{FeCp}_{2}$ results from the favorable intercolumnar interactions between the $\mathrm{C}-\mathrm{F}$ bond dipole moments and the $\mathrm{FeCp}_{2}$ molecule. This is in marked contrast to the behavior observed in $\left(\mathrm{C}_{6} \mathrm{~F}_{5}\right)_{2}: \mathrm{FeCp}_{2}$, which exhibits disorder of the $\mathrm{Cp}$ rings down to at least $120 \mathrm{~K}$ due to the $\left(\mathrm{C}_{6} \mathrm{~F}_{5}\right)_{2}$ molecule impeding sideways interactions with $\mathrm{FeCp}_{2}$ (see Figure $\left.\mathrm{S} 10\right) .{ }^{17}$ However, the co-crystal formed by $\mathrm{C}_{10} \mathrm{~F}_{8}$ and $\mathrm{FeCp}_{2}$ in a 2:1 ratio results in a columnar structure with alternating $\mathrm{FeCp}_{2}$ and $\mathrm{C}_{10} \mathrm{~F}_{8}$ molecules in which the $\mathrm{Cp}$ rings adopt an ordered arrangement at $223 \mathrm{~K}^{18}$ In addition, the second $\mathrm{C}_{10} \mathrm{~F}_{8}$ provides the strong sideways interaction with the $\mathrm{FeCp}_{2}$ molecule required to order the $\mathrm{Cp}$ rings (see Figure S11).

Attempts to produce a solvate with hot $\mathrm{C}_{6} \mathrm{H}_{6}$ analogous to the pyrene complex ${ }^{20}$ resulted in the growth of $\mathrm{FeCp}_{2}$ crystals as demonstrated by PXRD experiments. This may be due to unfavorable electrostatic interactions between $\mathrm{C}_{6} \mathrm{H}_{6}$ and $\mathrm{FeCp}_{2}$. Additionally, experiments involving $\mathrm{RuCp}_{2}$ dissolved in $\mathrm{C}_{6} \mathrm{H}_{6}$ and $\mathrm{C}_{6} \mathrm{~F}_{6}$ simply resulted in the formation of a massive $\mathrm{RuCp}_{2}$ single crystal from the former and polycrystalline material from the latter at room temperature, and no adduct.

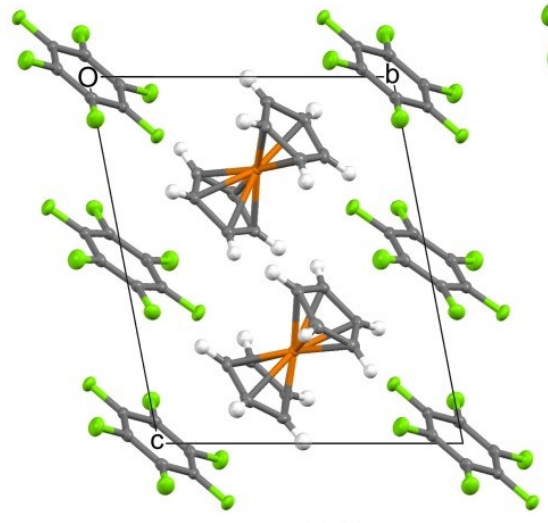

$100 \mathrm{~K}$

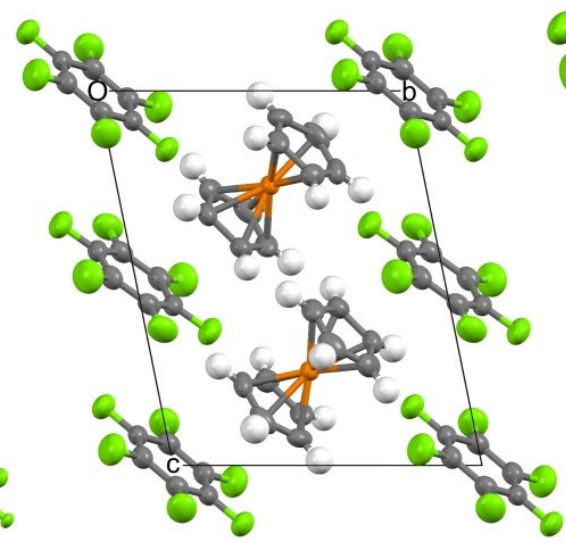

$250 \mathrm{~K}$

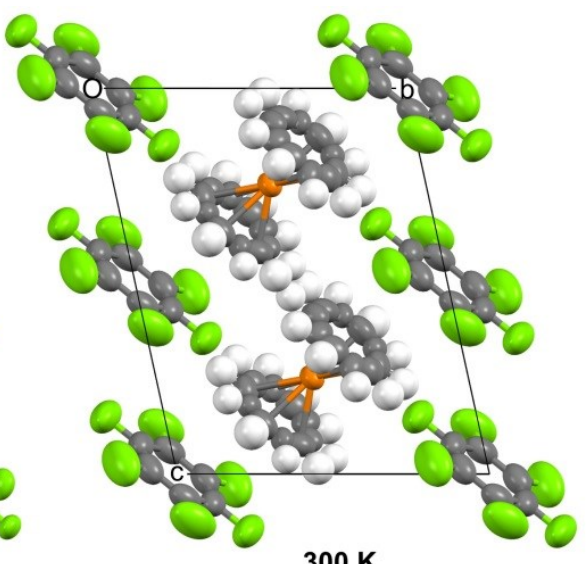

$300 \mathrm{~K}$

Figure 2. The crystal structure of $\mathrm{C}_{6} \mathrm{~F}_{6}: \mathrm{FeCp}_{2}$ viewed along a showing the evolution of the thermal motion as a function of temperature (from data measured at $100 \mathrm{~K}, 250 \mathrm{~K}$, and $300 \mathrm{~K}$ ), ultimately leading to complete disorder in phase I close to RT. Crystallographic labelling of the atoms in each phase is shown in Figure S1. Ellipsoids and spheres are drawn at $50 \%$ probability using the program Mercury ${ }^{31}$ from CCDC. 


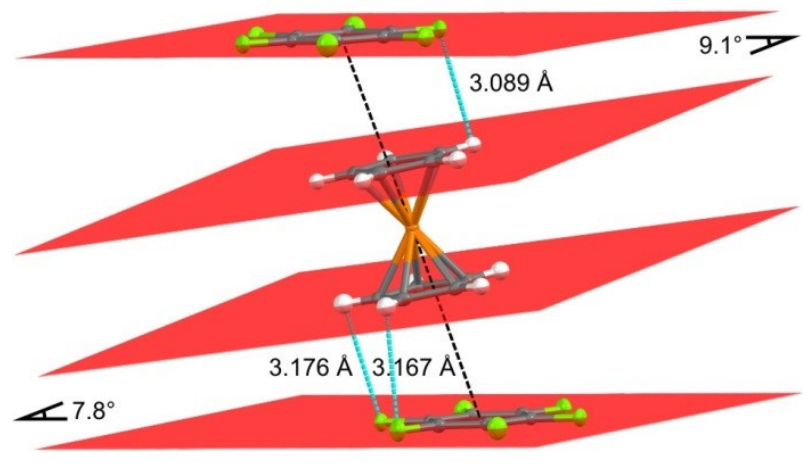

Figure 3. Figure showing the relative tilts of the two types of molecule in a column within the crystal structure of the ordered phase II of $\mathrm{C}_{6} \mathrm{~F}_{6}: \mathrm{FeCp}_{2}$ at $100 \mathrm{~K}$. A dashed black line passing through the centers of the $\mathrm{C}_{6} \mathrm{~F}_{6}$ molecules and the $\mathrm{Fe}$ atom shows the column axis. Least-squares planes through the 5- and 6membered rings, calculated with the program Mercury ${ }^{31}$ from CCDC, are shown in red. Closest interactions between $\mathrm{F}$ and $\mathrm{H}$ are shown with a dotted blue line.

In conclusion, this work demonstrates that a solvent molecule can dramatically change the physical property of a co-former in the solid state. In this case, the order-disorder transition in ferrocene was engineered to be $130 \mathrm{~K}$ higher by complexing with $\mathrm{C}_{6} \mathrm{~F}_{6}$. Our observations and results support the initial hypothesis about the predictive power of simple models of molecular electrostatics in crystal engineering, e.g. the interaction of the quadrupole moments of these planar molecules in defining the architecture of the adducts. The interactions studied herein are fundamental to the formation of all co-crystals or solvates dominated by weak electrostatic interactions and are of paramount importance in crystal structure prediction.

\section{ASSOCIATED CONTENT}

\section{Supporting Information}

The Supporting Information is available free of charge on the ACS Publications website.

Additional experimental detail, crystallographic tables, and additional supporting figures are supplied as a PDF file. CIF files have been deposited with the Cambridge Crystallographic Data Center with deposition numbers 1962531-1962540 (phase II) and 1962541-1962543 (phase I).

\section{AUTHOR INFORMATION}

\section{Corresponding Author}

*Email: j.k.cockcroft@ucl.ac.uk

\section{ORCID}

Jeremy Karl Cockcroft: 0000-0002-4954-651X

\section{Notes}

The authors declare no competing financial interests.

\section{ACKNOWLEDGMENT}

We acknowledge financial support from the EPSRC for funding the X-ray diffractometers (grant reference EP/K03930X/1). JCB thanks Kingston University for internal grant P1305-103. We thank Dr. Alexander Rosu-Finsen and Prof. Christoph G. Salzmann for use of their DSC calorimeter for low temperature studies on $\mathrm{FeCp}_{2}$ and Dr. Gareth Williams and Ms Yuying Pang of the School of Pharmacy, UCL, for help with additional DSC measurements on $\mathrm{C}_{6} \mathrm{~F}_{6}: \mathrm{FeCp}_{2}$ following reviewer feedback.

\section{REFERENCES}

(1) Kealy, T. J.; Pauson, P. L. A New Type of Organo-iron Compound. Nature, 1951, 168, 1039-1040.

(2) Pauson, P. L. Ferrocene-How It All Began. J. Organomet. Chem. 2001, 637-639, 3-6.

(3) Werner, H. At Least 60 Years of Ferrocene: The Discovery and Rediscovery of the Sandwich Complexes. Angew. Chem. Int. Ed. 2012, 51 (25), 6052-6058.

(4) Astruc, D. Why is Ferrocene so Exceptional? Eur. J. Inorg. Chem 2017, 2017 (1), 6-29.

(5) Inkpen, M. S.; Scheerer, S.; Linseis, M.; White, A. J. P.; Winter, R. F.; Albrecht, T.; Long, N. J. Oligomeric Ferrocene Rings. Nat. Chem. 2016, 8 (9), 825-830.

(6) Dunitz, J. D.; Orgel, L. E.; Rich, A. The Crystal Structure of Ferrocene. Acta Crystallogr. 1956, 9, 373-375.

(7) Edwards, J. W.; Kington, G. L.; Mason, R. The Thermodynamic Properties of Ferrocene. Part 1.-The Low-Temperature Transition in Ferrocene Crystals. Trans Faraday Soc 1960, 56 (0), 660-667.

(8) Brock, C. P.; Fu, Y. Rigid-Body Disorder Models for the HighTemperature Phase of Ferrocene. Acta Crystallogr. B 1997, 53 (6), 928938.

(9) Paliwoda, D.; Kowalska, K.; Hanfland, M.; Katrusiak, A. U-Turn Compression to a New Isostructural Ferrocene Phase. J. Phys. Chem. Lett. 2013, 4 (23), 4032-4037.

(10) Seiler, P.; Dunitz, J. D. Low-Temperature Crystallization of Orthorhombic Ferrocene: Structure Analysis at 98 K. Acta Crystallogr. B 1982, $38(6), 1741-1745$.

(11) Battaglia, M. R.; Buckingham, A. D.; Williams, J. H. The Electric Quadrupole Moments of Benzene and Hexafluorobenzene. Chem. Phys. Lett. 1981, 78 (3), 421-423.

(12) Ritchie, G. L. D.; Cooper, M. K.; Calvert, R. L.; Dennis, G. R.; Phillips, L.; Vrbancich, J. Molecular Quadrupole Moments, Magnetic Anisotropies, and Charge Distributions of Ferrocene and Ruthenocene. $J$. Am. Chem. Soc. 1983, 105 (16), 5215-5219.

(13) Patrick, C. R.; Prosser, G. S. A Molecular Complex of Benzene and Hexafluorobenzene. Nature 1960, 187 (4742), 1021-1021.

(14) Cockcroft, J. K.; Rosu-Finsen, A.; Fitch, A. N.; Williams, J. H. The Temperature Dependence of $\mathrm{C}-\mathrm{H} \cdots \mathrm{F}-\mathrm{C}$ Interactions in Benzene:Hexafluorobenzene. CrystEngComm 2018, 20 (42), 6677-6682.

(15) Cockcroft, J. K.; Ghosh, R. E.; Shephard, J. J.; Singh, A.; Williams, J. H. Investigation of the Phase Behaviour of the 1:1 Adduct of Mesitylene and Hexafluorobenzene. CrystEngComm 2017, 19 (7), 10191023.

(16) Cockcroft, J. K.; Li, J. G. Y.; Williams, J. H. Influence of MethylSubstitution on the Dynamics of the $\mathrm{C}-\mathrm{H} \cdots \mathrm{F}-\mathrm{C}$ Interaction in Binary Adducts. CrystEngComm 2019, 21 (37), 5578-5585.

(17) Batsanov, A. S.; Collings, J. C.; Marder, T. B. ArenePerfluoroarene Interactions in Crystal Engineering. XV. FerroceneDecafluorobiphenyl (1/1). Acta Crystallogr. C 2006, 62 (6), m229-m231.

(18) Clyburne, J. A. C.; Hamilton, T.; Jenkins, H. A. The Molecular Quadrupole Moment: Solid State Architectures Containing Organic and Organometallic Molecules. Cryst. Eng. 2001, 4 (1), 1-9.

(19) Rheingold, A. L. CCDC Deposition No. 1430306, Experimental Structure Determination 2015, https://doi.org/10.5517/cc1k0bxt

(20) Atencio, R.; Domasevitch, K. V.; Zaworotko, M. J. Synthesis and Single Crystal Structure of the 1:1 Binary Complex between Pyrene and Ferrocene. Cryst. Eng. 2000, 3 (1), 63-69.

(21) Cervantes-Lee, F.; Sharma, H. K.; Pannell, K. H.; DerecskeiKovacs, A.; Marynick, D. S. Conformational Preferences of 1,3Diferrocenyl-1,1,3,3-Tetramethyldisiloxane and Its Cocrystal with Ferrocene: A Theoretical and Crystallographic Study of the Role of Intra- and Intermolecular Interactions. Organometallics 1998, 17 (17), 3701-3706.

(22) Blanchard, M. D.; Hughes, R. P.; Concolino, T. E.; Rheingold, A. L. $\pi$-Stacking between Pentafluorophenyl and Phenyl Groups as a Controlling Feature of Intra- and Intermolecular Crystal Structure Motifs in Substituted Ferrocenes. Observation of Unexpected Face-to-Face Stacking between Pentafluorophenyl Rings. Chem. Mater. 2000, 12 (6), 16041610.

(23) Braga, D.; Luca Giaffreda, S.; Rubini, K.; Grepioni, F.; R. Chierotti, M.; Gobetto, R. Making Crystals from Crystals: Three Solvent-Free Routes to the Hydrogen Bonded Co-Crystal between 1,1'-DiPyridyl- Ferrocene and Anthranilic Acid. CrystEngComm 2007, 9 (1), 39 45.

(24) Müller, K.; Faeh, C.; Diederich, F. Fluorine in Pharmaceuticals: Looking Beyond Intuition. Science 2007, 317 (5846), 1881-1886. 
(25) Thalladi, V. R.; Weiss, H.-C.; Bläser, D.; Boese, R.; Nangia, A.; Desiraju, G. R. C-H $\cdots$ F Interactions in the Crystal Structures of Some Fluorobenzenes. J. Am. Chem. Soc 1998, 120 (34), 8702-8710.

(26) Collings, J. C.; Roscoe, K. P.; Robins, E. G.; Batsanov, A. S.; Stimson, L. M.; Howard, J. A. K.; Clark, S. J.; Marder, T. B. ArenePerfluoroarene Interactions in Crystal Engineering 8: Structures of 1:1 Complexes of Hexafluorobenzene with Fused-Ring Polyaromatic Hydrocarbons. New J. Chem. 2002, 26 (12), 1740-1746.

(27) Vanspeybrouck, W.; Herrebout, W. A.; van der Veken, B. J.; Lundell, J.; Perutz, R. N. Direct Measurement of the Stability of the Supramolecular Synthon $\mathrm{C}_{6} \mathrm{H}_{6}: \mathrm{C}_{6} \mathrm{~F}_{6}$. J. Phys. Chem. B 2003, 107 (50), $13855-$ 13861.

(28) Braga, D., Grepioni, F. Crystal Construction and Molecular Interplay in Solid Ferrocene, Nickelocene, and Ruthenocene. Organometallics 1992, $11(2), 711-718$.

(29) Islam, M. T., Best, S. P., Bourke, J. D., Tantau, L. J., C. Q. Tran, C. Q., Wang, F., Chantler, C. T. Accurate X-ray Absorption Spectra of Dilute Systems: Absolute Measurements and Structural Analysis of Ferrocene and Decamethylferrocene. J. Phys. Chem. C 2016, 120 (17), 93999418.

(30) Malenov, D. P., Antonijević, I. S., Hall, M. B., Zarić, S. D. Stacking of Cyclopentadienyl Organometallic Sandwich and Half-sandwich Compounds. Strong Interactions of Sandwiches at Large Offsets. CrystEngComm, 2018, 20 (31), 4506-4514.

(31) Macrae, C. F.; Bruno, I. J.; Chisholm, J. A.; Edgington, P. R.; McCabe, P.; Pidcock, E.; Rodriguez-Monge, L.; Taylor, R.; van de Streek, J.; Wood, P. A. Mercury CSD 2.0 - New Features for the Visualization and Investigation of Crystal Structures. J. Appl. Crystallogr., 2008, 41 (2), 466-470.

FOR TABLE OF CONTENTS ONLY

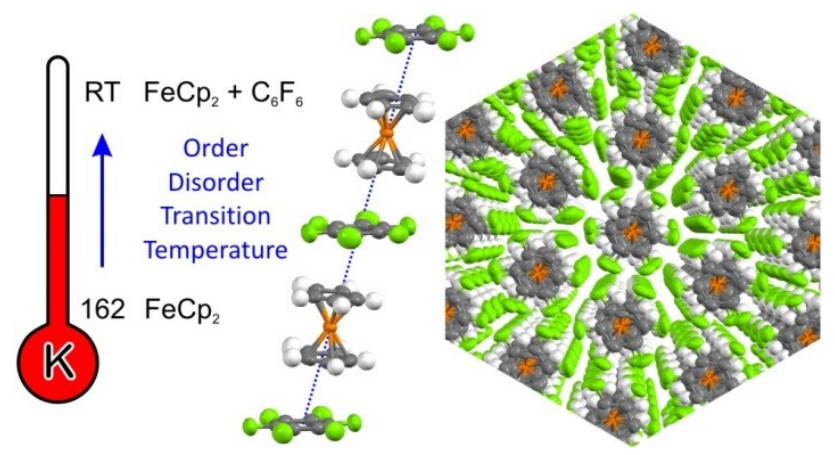

